\title{
Thelytokous parthenogenesis, male clonality and genetic caste determination in the little fire ant: new evidence and insights from the lab
}

\author{
$\mathrm{J} \mathrm{Foucaud}^{1,3}$, A Estoup ${ }^{1}$, A Loiseau ${ }^{1}, \mathrm{O} \mathrm{Rey}^{1}$ and J Orivel ${ }^{2}$ \\ ${ }^{1} I N R A$, UMR CBGP (INRA/IRD/Cirad/Montpellier SupAgro), Campus international de Baillarguet, Montferrier-sur-Lez, France and \\ ${ }^{2}$ Laboratoire Evolution et Diversité Biologique, UMR-CNRS 5174, Université Toulouse III, 118 route de Narbonne, Toulouse, France
}

\begin{abstract}
Previous studies indicate that some populations of the little fire ant, Wasmannia auropunctata, display an unusual reproduction system polymorphism. Although some populations have a classical haplodiploid reproduction system, in other populations queens are produced by thelytokous parthenogenesis, males are produced by a male clonality system and workers are produced sexually. An atypical genetic caste determination system was also suggested. However, these conclusions were indirectly inferred from genetic studies on field population samples. Here we set up experimental laboratory nests that allow the control of the parental relationships between individuals. The queens heading those nests originated from either putatively clonal or sexual populations. We character-
\end{abstract}

ized the male, queen and worker offspring they produced at 12 microsatellite loci. Our results unambiguously confirm the unique reproduction system polymorphism mentioned above and that male clonality is strictly associated with thelytokous parthenogenesis. We also observed direct evidence of the rare production of sexual gynes and arrhenotokous males in clonal populations. Finally, we obtained evidence of a genetic basis for caste determination. The evolutionary significance of the reproduction system polymorphism and genetic caste determination as well as future research opportunities are discussed.

Heredity (2010) 105, 205-212; doi:10.1038/hdy.2009.169; published online 25 November 2009

Keywords: reproduction system; thelytokous parthenogenesis; male clonality; genetic caste determination; Wasmannia auropunctata

\section{Introduction}

Understanding the evolution of the wide diversity in reproduction systems is a major goal in evolutionary biology (Maynard Smith, 1978; Bell, 1982; Normark, 2003). A promising pathway to fulfil this ambition is the uncovering and careful study of extant organisms showing both sexual and asexual reproduction (for example, see Vrijenhoek, 1993; Kearney and Shine, 2004).

Recent genetic studies on the little fire ant, Wasmannia auropunctata, highlight the coexistence of two distinct reproduction systems, both indirectly inferred from the genotyping of individuals sampled in the field (Figure 1; Fournier et al., 2005a; Foucaud et al., 2007). The first reproduction system indirectly inferred is haplodiploidy (sensu Normark, 2003; that is, fertilized, diploid eggs produce female queens and workers and unfertilized, haploid eggs produce arrhenotokous males), which is classically the rule for Formicidae (Hölldobler and Wilson, 1990). This reproduction system will be hereafter referred to as 'sexual reproduction'. The second

Correspondence: Dr J Foucaud, Laboratoire Evolution, Génomes, Spéciation, UMR-CNRS 9034, Avenue de la Terrasse, Bat 13-Avenue de la Terrasse, Gif-sur-Yvette 91198, France.

E-mail: julien.foucaud@legs.cnrs-gif.fr

${ }^{3}$ Current address: Laboratoire Evolution, Génomes, Spéciation, UMRCNRS 9034, Avenue de la Terrasse, 91198 Gif-sur-Yvette, France.

Received 4 September 2009; revised 22 October 2009; accepted 30 October 2009; published online 25 November 2009 reproduction system indirectly inferred from field populations is more unusual, but not unique (Ohkawara et al., 2006), as it includes three distinct types of offspring production, one for each caste and sex (Fournier et al., 2005a). Female queens are produced by thelytokous parthenogenesis (that is, diploid females produced uniquely by female genetic material), males are produced through a male clonality system (that is, males are genetically identical to their haploid father, although laid by queens) and female workers are produced sexually (Figure 1). This reproduction system will be hereafter referred to as 'clonal reproduction'. Previous genetic data from field population samples also indicated that sexual queens and arrhenotokous males might be still rarely produced within populations displaying clonal reproduction (Foucaud et al., 2006).

Some W. auropunctata populations may also possess another unusual feature: a genetic caste determination system (that is, a genetic influence over the determination of the queen versus worker phenotype), at least in clonal populations (Foucaud et al., 2006). Previous field genetic studies on $W$. auropunctata indicate that, in clonal populations, thelytokous individuals were most probably targeted to the reproductive caste (that is, queens) whereas sexual individuals were almost invariably directed to the worker caste, with some rare exceptions (Foucaud et al., 2006). This pattern suggests that the caste fate of diploid eggs may have a genetic basis in W. auropunctata. However, in ants, the caste fate of a 


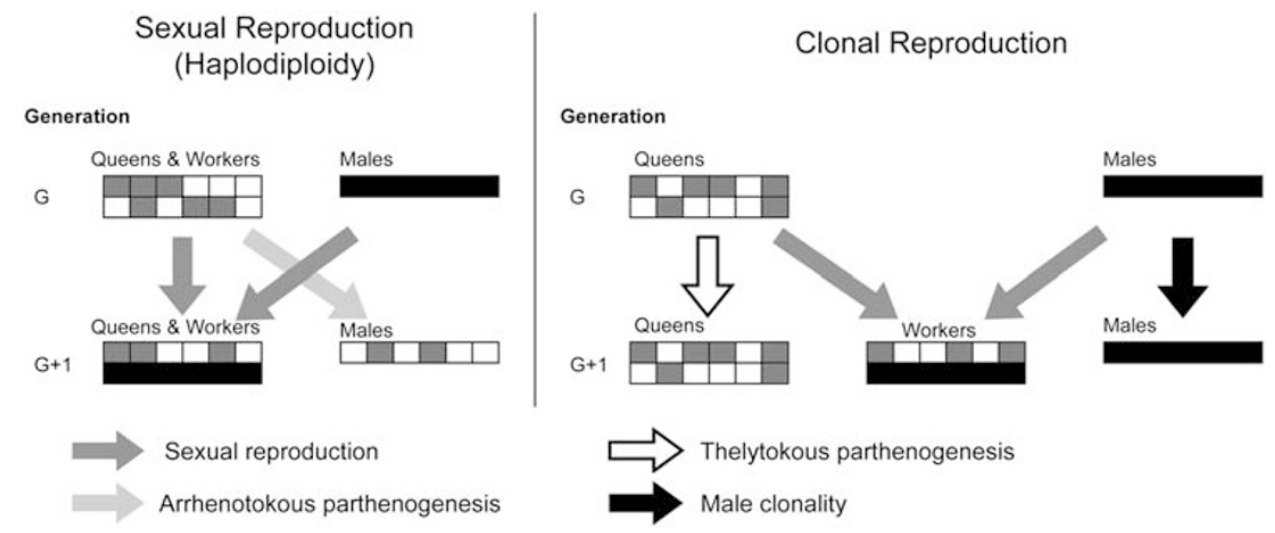

Figure 1 Schematic representation of the gene transmission between two consecutive generations in the two types of reproduction system found in W. auropunctata. Note: individual genotypes are represented by rectangles (diploid females: two lines; haploid males: one line), constituted of several loci represented by squares (white and gray squares: 'female' alleles; black squares: 'male' alleles). Sexuality, arrhenotokous parthenogenesis, thelytokous parthenogenesis and male clonality events are represented by dark gray, light gray, white and black arrows, respectively. It should be noted that clonal males are produced from eggs laid by female queens.

particular diploid egg (that is, queen or worker) is generally thought to be environmentally driven and controlled by the workers (Hölldobler and Wilson, 1990; Crozier and Pamilo, 1996; Queller and Strassmann, 1998). The genetic content of diploid eggs has been shown to influence its caste fate in only a few ant species (Fraser et al., 2000; Helms Cahan et al., 2004; Anderson et al., 2008a). As a consequence, genetic effects on caste determination are thought to be relatively rare in eusocial species (Crozier and Pamilo, 1996, but see Anderson et al., 2008a; Lo et al., 2009).

In this study, we seek to replace the indirect inferences accumulated so far in $W$. auropunctata with direct and unambiguous evidence of (i) a reproduction system polymorphism (that is, sexual and clonal populations), and (ii) a genetic caste determination system (that is, a genotype influence on caste). To this end, we set up experimental nests in the laboratory, each with a single mothering genotype, and characterized at 12 microsatellite loci the reproductive and worker offspring they produced. Unlike previous population genetic studies, our laboratory-nest design allowed the control of both the number of egg-laying queens and parental relationships between these queens and their male, queen and worker offspring.

\section{Materials and methods}

\section{Sampling and experimental conditions}

We collected 132 queens and several thousand workers from nine populations from French Guiana and New Caledonia (Table 1). On the basis of previous genetic studies of population samples collected in the field at same locations (Foucaud et al., 2006, 2007), we could predict that three of the collected populations were probably sexual and six were probably clonal (Table 1).

We set up 117 experimental nests, the large majority of them being mothered by a single dealate queen $(n=112)$, and a few of them including four dealate queens (only for one putatively clonal population with a single queen genotype, $n=5)$. These queens will be hereafter referred to as F0 queens. All nests were initially founded with at least 200 workers from the same population as the queen.
These nests were held in climate chambers at a constant temperature of $25^{\circ} \mathrm{C}$ and at a $65 \%$ humidity rate. Food (sugar water and mealworms) was provided ad libitum. For each nest, we collected at the pupal stage all reproductive individuals (queens and males) as well as a dozen workers; collecting offspring at the pupal stage allowed to distinguish castes by morphology and ensured that all have been produced by the mothering F0 queen after the setting up of the experimental nest. This offspring will be hereafter referred to as F1 queens, males or workers. The F1 reproductive individuals were collected after a couple of months and until 1.5 years after the beginning of our experimental setup. We also collected around 20 F1 adult workers in each experimental nests older than 90 days (cf. life expectancy of $W$. auropunctata workers was measured to be around 30 days; Ulloa-Chacon, 1990). Finally, F0 mother queens were collected when they died or at the end of the nest-rearing experiment (that is, after 1.5 years for the oldest nests).

We also tested whether virgin queens (that is, F1 alate gynes produced by our F0 queens) from both clonal and sexual populations could produce viable offspring, with a particular interest in the possibility of virgin parthenogenetic queens to produce queen daughters. To this end, we set up two types of nests: 15 parthenogenetic gynes were installed in individual nests and 15 parthenogenetic gynes and 14 sexual gynes were installed in seven nests containing one to six gynes according to their population of origin. About 0-100 workers of the corresponding population were added into every nest. Nutritional resources were added equally and simultaneously to all other experimental nests. Some experiments that we carried out independently indicated that newly mated queens produced their first adult offspring after a single month (unpublished data). We therefore conducted this experiment on virgin queens for over four months (or less when a gyne died) to control for an effect of the gyne age on its production of adult offspring. It is important to note that there is no obligatory mating flight for $W$. auropunctata queens, as observed both in the field and in our experimental stock colonies. We recorded whether eggs, larvae and adults were produced every 2-3 days. 
Table 1 Numbers and origin of laboratory-settled nests and number of produced gynes and males

\begin{tabular}{|c|c|c|c|c|c|}
\hline $\begin{array}{l}\text { Sampled } \\
\text { site }\end{array}$ & $\begin{array}{l}\text { Putative reproduction } \\
\text { system }\end{array}$ & $\begin{array}{l}\text { Number of } \\
\text { laboratory-settled nests }\end{array}$ & $\begin{array}{l}\text { Number of nests with } \\
\text { produced reproductives (gynes/males) }\end{array}$ & $\begin{array}{l}\text { Number of } \\
\text { produced gynes }\end{array}$ & $\begin{array}{l}\text { Number of } \\
\text { produced males }\end{array}$ \\
\hline Ker & Clonal & 20 & $10(9 / 5)$ & 32 & 8 \\
\hline RN & Clonal & 15 & $2(2 / 1)$ & 2 & 1 \\
\hline M6-C & Clonal & 13 & $1(1 / 0)$ & 15 & 0 \\
\hline M3-P & Clonal & 2 & 0 & 0 & 0 \\
\hline P2 & Clonal & 15 & $2(2 / 1)$ & 3 & 1 \\
\hline $\mathrm{NC}$ & Clonal & 6 & 0 & 0 & 0 \\
\hline M7 & Sexual & 29 & $13(11 / 4)$ & 109 & 23 \\
\hline M3-F & Sexual & 14 & $6(6 / 0)$ & 51 & 0 \\
\hline M6 & Sexual & 3 & 0 & 0 & 0 \\
\hline Total & & 117 & $34(31 / 11)$ & 212 & 33 \\
\hline
\end{tabular}

Names and locations of collection sites are identical to those in the study by Foucaud et al., 2007.

\section{Genetic analyses}

Following Fournier et al. (2005b), we extracted DNA from all reproductives produced in our experimental nests, together with at least eight workers (pupae, adults or both). When possible, we extracted the DNA from their mother queen as well as the spermathecal content of the latter to directly obtain the genotypes of the mother and of the fathering male. In some cases, the mother queen could not be collected because it had died and was not found again. For these nests, however, we could easily infer the mother and father genotypes from the genotypes of the workers (see Results section).

A total of 616 specimens were genotyped at 12 microsatellite loci, as described in the study by Fournier et al., 2005b). The numbers and types of genotyped specimens (queens, males and workers) are detailed in Table 2. The PCR products were separated on a MegaBace DNA sequencer (GE Healthcare Bio-Sciences, Uppsala, Sweden) and gel files were analyzed using GENETIC PROFILER (GE Healthcare Bio-Sciences).

\section{Statistical analysis and interpretation of data}

To infer the reproduction systems of our laboratory families, the relationship between parents and offspring genotypes was investigated both visually and with the help of a personal programme identifying identical multilocus genotypes (can be made available by the authors on request). The identification of the modes of production of each caste and sex was straightforward. For a female offspring, if her multilocus genotype is identical to the genotype of the parental female genotype, then parthenogenetic (thelytokous) production is supported. If the genotype is a combination of half of male and female parental genotypes at each locus, then sexual production is supported. For a haploid male offspring, if his multilocus genotype is identical to the parental male genotype, then clonal production is supported. If it is a combination of one of the queen's alleles at each locus, then arrhenotokous parthenogenesis (that is, 'sexual' production, according to our previous definition) is supported. It should be noted that workers are sterile in this species (Ulloa-Chacon and Cherix, 1988), so that males could only be produced by the queen.

The co-occurrence of parthenogenetic and sexual modes of female offspring production (that is, queen and workers) found in the clonal populations of $W$. auropunctata provides an opportunity to test whether the caste is genetically determined in this species. If the caste is genetically determined, we expect that (i) the parthenogenetic females produced by a thelytokous mother queen will be all targeted toward the queen caste and (ii) most sexually produced female offspring will be targeted to the worker caste. This is because the genetic combination needed for the queen phenotype is likely to be broken by recombination and the male's genetic contribution. On the contrary, if the caste is environmentally determined, we expect no significant relationship between the mode of production and caste fate for the female offspring. Using the data we obtained from the 14 clonal laboratory-settled nests that produced both female reproductives (that is, F1 gynes) and workers, we have statistically tested the association between the mode of offspring production (parthenogenetic or sexual) and the offspring caste (queen or worker) using a Fisher's exact test. The total amount of data for this test was 265 individuals (52 gynes and 213 workers). Our approach is similar to that used in previous studies dealing with genetic caste determination in social insects (for example, see Fraser et al., 2000; Smith et al., 2008).

We also searched for some evidences of a genetic caste determination mechanism in the sexual population samples by testing for a genetic differentiation at our 12 microsatellite loci between gynes and workers. Following Schwander et al. (2007a), we considered in each sexual population the sampled gynes and workers as two genetic groups and tested the significance of $\mathrm{F}_{\mathrm{ST}}$ values computed at each microsatellite locus and overall loci. Significance of the overall loci and locus-by-locus $\mathrm{F}_{\mathrm{ST}}$ values were tested by randomizing genotypes among genetic groups (10000 randomizations) using FSTAT (Goudet, 2001).

It is worth pointing that, in some rare cases, parthenogenetic production of females is not strictly synonymous with identical genotypes between queen and daughter gynes in W. auropunctata depending on the type of thelytokous parthenogenesis occurring (Foucaud et al., 2006). This survey allows the computation of the rate of locus homogenization (that is, the conversion of a heterozygous locus into a locus homozygous for one of the two maternal alleles) during thelytokous parthenogenesis (Foucaud et al., 2006; Pearcy et al., 2006). This rate allows, at least theoretically, the discrimination between the types of thelytoky displayed by parthenogenetic organisms. Basically, automictic organisms (that is, whose parthenogenesis involve meiosis) commonly 
Table 2 Reproduction system for the gynes, males and workers produced in laboratory nests, inferred from multilocus genotypic data

\begin{tabular}{|c|c|c|c|c|c|c|c|c|c|}
\hline \multirow{2}{*}{$\begin{array}{l}\text { Putative } \\
\text { reproduction } \\
\text { system }\end{array}$} & \multirow{2}{*}{$\begin{array}{c}\text { Number of } \\
\text { laboratory-settled } \\
\text { nests }\end{array}$} & \multirow{2}{*}{$\begin{array}{l}\text { Number of nests with } \\
\text { produced reproductives } \\
\text { (gynes/males) }\end{array}$} & \multicolumn{2}{|c|}{$\begin{array}{c}\text { Number of produced } \\
\text { gynes }\end{array}$} & \multicolumn{2}{|c|}{$\begin{array}{c}\text { Number of produced } \\
\text { males }\end{array}$} & \multicolumn{2}{|c|}{$\begin{array}{c}\text { Number of produced } \\
\text { workers }\end{array}$} & \multirow[t]{2}{*}{ Total } \\
\hline & & & Clonal & Sexual & Clonal & Sexual & Clonal & Sexual & \\
\hline Clonal & 71 & $15(14 / 7)$ & 51 & 1 & 7 & 3 & 10 & 203 & 275 \\
\hline Sexual & 46 & $19(17 / 4)$ & 0 & 160 & 0 & 23 & 0 & 158 & 341 \\
\hline Total & 117 & $34(31 / 11)$ & 51 & 161 & 7 & 26 & 10 & 361 & 616 \\
\hline
\end{tabular}

All reproductives and only a subset of workers were genotyped.

exhibit high rates of locus homogenization (for example, from $1 / 3$ for loci independent from the centromeres to 1.0 for a gamete duplication mechanism; see Oldroyd et al., 2008), whereas apomictic organisms (that is, whose parthenogenesis do not involve meiosis) usually exhibit low rates of locus homogenization (typically $r=0.0$; but see Baudry et al., 2004). Here we computed the rate of locus homogenization independently for each locus. We averaged the number of homogenization events over the number of thelytokous individual heterozygous for each particular locus ( $n=1-61$ individuals depending on the investigated locus).

\section{Results}

\section{Production of gynes}

The F0 queens (that is, mother queens) in 31 of our 117 experimental nests produced F1 gynes (14 and 17 queens from putatively clonal and sexual populations, respectively; Tables 1 and 2). A total of 51 gynes of the 52 produced by a queen originating from a putatively clonal population displayed a multilocus genotype identical to the genotype of their mother (except one homogenization event, see below), and did not bear any allele of the male mated to their mother (see Supplementary Table S1 for an illustration). This result demonstrates unambiguously the occurrence of thelytokous parthenogenesis in a subset of W. auropunctata populations. We also found that a single gyne was produced sexually by a queen that also produced two parthenogenetic gynes (Table 2 and see Supplementary Table S3 for an illustration). Therefore, although the vast majority of gyne offspring is produced through thelytokous parthenogenesis, at least some of the thelytokous queens retain the ability to produce gynes sexually. In agreement with indirect evidences from field studies, we observed a low rate of locus homogenization during the thelytokous production of new parthenogenetic queens (mean $r=0.13 \%$ overall loci with single locus $r$ values ranging from 0 to $1.64 \%$ ).

We found that all 160 gynes laid by queens originating from putatively sexual populations were sexually produced (Table 2 and see Supplementary Table S2 for an illustration). No parthenogenetic reproduction event was identified for those queens. This result demonstrates that gynes are exclusively produced sexually in another set of W. auropunctata populations.

Interestingly enough, four of the 44 isolated F1 virgin queens originating either from clonal or sexual populations produced few to many eggs; none of these eggs could develop into pupae (worker, gyne or male), and this during more than four months of experiment.

\section{Production of males}

On 117 experimental nests, the F0 queens of 11 nests produced F1 males during our experiment (seven and four queens from putatively clonal and sexual populations, respectively; Table 1). A majority of males produced by queens isolated from putatively clonal populations displayed a multilocus genotype identical to that of their father and did not bear any allele of their mother $(n=7$; Table 2 and see Supplementary Table S1 for an illustration). This pattern clearly demonstrates the occurrence of male clonality in some $W$. auropunctata populations. However, one parthenogenetic queen also produced three males through classical arrhenotokous parthenogenesis (in addition to one clonal male; Supplementary Table S3). The production by parthenogenetic queens of new males through classical arrhenotoky is therefore feasible.

We found that all 23 males laid by queens isolated from putatively sexual populations were produced by arrhenotokous parthenogenesis (Table 2 and see Supplementary Table S2 for an illustration). We did not observe any clonal reproduction events for those queens. This result demonstrates the occurrence of only classical sexual production of males in some other W. auropunctata populations.

It is worth pointing that all clonal males $(n=7)$ were produced by queens also producing parthenogenetic gynes. Male clonality was thus strictly associated to thelytokous parthenogenesis.

\section{Production of workers}

We observed that a very large majority of workers (361 workers from all genotyped nests) were produced sexually regardless of the mode of production of gyne and male offspring (Table 2). In all nests for which the genotypes of both the F0 queen and her spermathecal content could be directly obtained, workers displayed a genotype demonstrating their sexual production (that is, at each locus, one of the two alleles of the worker genotype was present in the F0 queen genotype and the other one present in the spermathecal content genotype; see Supplementary Tables S1 and S2 for illustrations). Monoandry (that is, a single fathering male for each queen) was also obvious from these data. This important observation allowed us to safely infer the parental genotypes from worker genotypes, in those experimental nests for which the queen or male genotypes could not be directly determined.

Interestingly, we found some worker genotypes that did not fit the above reproduction rules in a single clonal nest (Table 2 and see Supplementary Table S1 for an illustration). In this nest, the large majority of adult 
workers were sexually produced but most pupae, as well as two adults, displayed a multilocus genotype identical to the genotype of their mother and did not bear any allele of their mother's male mate. This small set of workers, mostly composed of pupae, was thus produced by thelytokous parthenogenesis.

\section{Caste determination}

Within clonal populations, we genotyped a total of 52 gynes (51 parthenogenetic and 1 sexual) and 213 workers (10 parthenogenetic and 203 sexual; Table 2). Parthenogenetic diploid eggs were hence significantly more directed toward the royal caste than sexual diploid eggs (Fisher's exact test: $P<10^{-6}$ ). This result holds when considering independently each set of parthenogenetic queens originating from different populations and that were characterized by different microsatellite genotypes (all $P<10^{-6}$ ). It is also worth stressing that the only parthenogenetic queen laying clonal eggs directed toward the worker caste produced adult workers at a very low rate (cf. most worker larvae did not complete their development). Although most pupal workers laid by this particular queen were parthenogenetic, most of the few adult workers were sexually produced. In clonal populations, we thus observed a clearly disproportionate allocation of individuals between castes depending on production mode, together with a high parthenogenetic worker mortality during development.

Regarding sexual populations, we found that gynes and workers directly sampled within two field populations were genetically different, as evidenced by low but significantly different from zero $\mathrm{F}_{\mathrm{ST}}$ values computed overall microsatellite loci (population M7: $\mathrm{F}_{\mathrm{ST}}=$ $0.017 \pm 0.005, P=0.006$; population $\mathrm{M} 3-\mathrm{F}: \mathrm{F}_{\mathrm{ST}}=0.026 \pm$ $0.005, P=0.006)$. Single locus $F_{\mathrm{ST}}$ values were significantly different at four (M3-F) and six (M7) loci, with only one locus showing significant differences in common for both populations.

\section{Discussion}

This study provides, to the best of our knowledge, the first direct experimental evidence of the co-occurrence of thelytokous parthenogenesis and male clonality within some populations of $W$. auropunctata (that is, 'clonal' populations). Thelytokous parthenogenesis is relatively common in insects (Normark, 2003), and has already been observed in seven ant species (see references in the study by Himler et al., 2009). On the contrary, the male clonality system demonstrated here is extremely rare (McKone and Halpern, 2003). Alternative variants of androgenesis have only been evidenced twice in insects and four times in all lifeforms (in Vollenhovia emeryi, Ohkawara et al., 2006; in Bacillus stick insects, Mantovani et al., 2001; in Corbicula clams, Komaru et al., 1998; and in the desert tree Cupressus dupreziana, Pichot et al., 2001). In these cases, androgenesis occurred through a variety of mechanisms, such as through the syngamy of two spermatozoa in Bacillus (Tinti and Scali, 1996), or unreduced triploid spermatozoa in Corbicula (Komaru et al., 1998). The androgenetic system found in $W$. auropunctata is original in that clonal males remain haploid (as measured by flow cytometry; Fournier et al., 2005a) and that workers are still produced through standard sexuality. Although sterile, workers are crucial to the fitness of queens and males. Interestingly enough, the joint occurrence of thelytoky and androgenesis in queens and males would theoretically avoid inbreeding depression and enable specific worker genomic combinations to be maintained over time. This system might enable workers to experience an increased niche breadth, as suggested for other ant species displaying separate male and female gene pools, through different hybridization mechanisms (Umphrey, 2006; Anderson et al., 2008b).

A particular finding, not to be overlooked, is the rare production of sexual gynes and arrhenotokous males in otherwise clonal populations. This result echoes indirect evidence obtained from an extensive population genetic survey of $W$. auropunctata in New Caledonia (Foucaud et al., 2006). Even at low frequency, these events are most likely of evolutionary importance, especially in the case of geographically isolated invasive populations such as those in New Caledonia. Such rare events might indeed disrupt the putative advantages of clonality by increasing genetic drift, inbreeding depression and diploid male load, and by breaking genomic combination potentially adapted to the new invaded environments (Foucaud et al., 2006).

Our experimental results do not permit to favor any current hypothesis on the mechanisms of the clonal reproduction system. We found low rates of single locus homogenization during female parthenogenesis (single locus rates ranging from 0 to $1.64 \%$ ). Although estimated from a relatively low number of individuals (from 1 to 61 individuals depending on the locus), such low rate values favor an apomictic mechanism associated with rare gene conversion events rather than automixis with central fusion (our 12 microsatellite loci are indeed unlikely to be all close to centromeres). This result echoes that found in the study on Platythyrea punctata (Schilder et al., 1999), but contrasts with the automixis mechanism inferred on another thelytokous ant species, Cataglyphis cursor (Pearcy et al., 2006) and to the Cape honeybee (Baudry et al., 2004; Oldroyd et al., 2008). Our results regarding the male clonality system do not allow to discard either of the two current mechanical hypothesis (that is, 'maternal genome elimination' and 'anucleate ovules'; Fournier et al., 2005a; Foucaud et al., 2007). We are currently running some reciprocal crossing experiments using sexual and clonal males and females to investigate this issue. Cytological investigations of $W$. auropunctata gametogenesis are also required to get a clearer view on the mechanisms involved in both clonal reproduction systems. Beside the above mechanical issues, $W$. auropunctata represents a promising biological model to unravel the genetic bases of male clonality and thelytokous parthenogenesis using large-scale genomic tools.

Our 30 isolated virgin queens originating from clonal populations did not produce any pupa of worker, queen or male. This result suggests that the parthenogenetic production of queens may require mating to occur. Alternative hypotheses, such as the age of the gynes, the resources intake or the necessity of flying cannot be discarded, but seem, however, unlikely due to our experimental procedure and previous observations (see Materials and methods section for details). Some (alated) gynes produced a large amount of eggs indicating that dealation is not necessary to lay eggs as in Lasius niger 
queens (Jemielity et al., 2006). None of those eggs could reach the pupal stage, however, indicating a developmental rather than a resource issue. Consequently, unmated gynes from clonal populations seem unable to directly benefit from thelytokous parthenogenesis to achieve some reproductive success.

This experimental study provides direct evidence that a standard sexual reproduction system is fully effective in some other $W$ auropunctata populations (that is, the so-called sexual populations). We therefore unambiguously confirmed the polymorphism of reproduction system inferred indirectly from previous genetic studies on $W$. auropunctata population samples taken in the field at the same locations (Fournier et al., 2005a; Foucaud et al., 2006, 2007). In other species showing such a reproduction system polymorphism, the balance between the sexual and clonal reproduction system is usually best explained by environmental conditions, whether abiotic (for example, seasonal climatic variation in Myzus persicae; Vorburger et al., 2003) or biotic (for example, prevalence of parasites; Lively et al., 1990). As W. auropunctata is an invasive species found in both natural and human-altered habitats (Tennant, 1994; Wetterer and Porter, 2003; Orivel et al., 2009), it would be worth studying the ecology of clonal and sexual populations to gain insight into both the evolution of reproduction systems diversity and of invasiveness.

Our experimental laboratory study provides evidence for a genetic basis for caste determination in $W$. auropunctata, at least in clonal populations. Genetic caste determination (most notably in dependent lineages of Pogonomyrmex; Julian et al., 2002; Volny and Gordon, 2002; Helms Cahan et al., 2004; Schwander et al., 2007a), or at least some genetic influence on caste fate (Fraser et al., 2000; Hughes et al., 2003), have been demonstrated several times in Formicidae (for review, see Anderson et al., 2008a). In the case of the clonal populations of $W$. auropunctata, only $1.9 \%$ of all $W$. auropunctata adult females did not comply with expectations based on a purely genetic determination of caste (one adult queen on 52 sampled and two adult workers on 104 sampled). This figure is similar to the observed proportion of Pogonomyrmex adult females not complying with a purely genetic caste determination (1.9\%; three adult queens on 80 sampled and zero adult worker on 75 sampled; Helms Cahan and Keller, 2003). Alternatively to genetic caste determination, one could also consider that these results are the consequence of a cyclical parthenogenesis mechanism with some environmental conditions favoring the development of queens or workers only. However, all W. auropunctata workers and gynes were sampled and hence produced simultaneously in each individual laboratory nest. The occurrence of both parthenogenetic and sexual worker pupae in the only nest in which thelytokous adult workers were sampled also confirms that clonal and sexual eggs are produced simultaneously by parthenogenetic queens. As a consequence, a cyclical parthenogenesis mechanism seems highly unlikely to account for the observed partition of genotypes in each caste. As we showed here, certain types of genotypes are largely constrained in their development and caste fate, and thus caste determination can be considered to be genetically hardwired in W. auropunctata. The correlation between genotype and caste observed in clonal populations was also indirectly detected, although much less clearly, in sexual populations, in which we observed a low but significant genetic differentiation between gynes and workers. No cyclical parthenogenesis mechanism could account for this latter result because all gynes and workers are sexually produced. One explanation could be that queens undergo multiple matings and that different patrilines show a bias in which female caste they produced, as inferred for Pogonomyrmex badius (Smith et al., 2008), Acromyrmex echinatior (Hughes et al., 2003) or Pogonomyrmex rugosus (Schwander and Keller, 2008). However, our results clearly indicate that $W$. auropunctata queens mate only once. An alternative explanation could be that, at least in sexual populations, different queens invest differently in queen and worker castes (that is, reproductive skew), as inferred for many ant species, such as Formica exsecta (Kummerli and Keller, 2007) or Formica fusca (Bargum and Sundstrom, 2007). This hypothesis deserves further investigations.

It is worth noting that strong genetic effects over caste determination in social Hymenoptera (see Anderson et al., 2008a) has only been demonstrated in species displaying unusual breeding patterns, which prevented normal segregation of genetic markers. This includes hybridization in the $P$. rugosus $-P$. barbatus complex (Anderson et al., 2006; Schwander et al., 2007a, b) and in the Solenopsis geminata $\times$ S. xyloni complex (Helms Cahan and Vinson, 2003), parthenogenesis in Vollenhovia emeryi (Ohkawara et al., 2006) and in W. auropunctata (this study). This feature might actually simply reflect the fact that microsatellite markers are traditionally used in studies dealing with reproduction systems. For W. auropunctata as for other species displaying 'strong' genetic caste determination (GCD; see Anderson et al., 2008a), hybridization or thelytokous parthenogenesis, in preventing gene flow between the male and female gene pools, necessarily linked all female genes (including the one(s) responsible for GCD) to a large part of microsatellite alleles at each locus, hence the 'strong' signal of GCD (and its detection even using low numbers of microsatellite loci randomly located on the genome; Ohkawara et al., 2006; Schwander et al., 2007a). In contrast, other breeding systems that include sexual recombination of male and female gene pools necessarily lead to 'weaker' correlations between microsatellite genotypes and caste (as in W. auropunctata sexual populations, or in so-called 'weak' GCD species, Anderson et al., 2008a). Thus, these 'strength' differences in GCD may only reflect different breeding systems and not necessarily different mechanisms of caste determination, which could be under the control of various amounts of genes (see Anderson et al., 2008a). In the case of W. auropunctata, there is hence no evidence that the GCD could be 'weaker' or different in sexual compared with clonal populations (sexual populations are most probably ancestral to clonal ones; Foucaud et al., 2007). This study as well as previous ones advocate for specific studies of caste determination in social Hymenoptera using appropriate large-scale genomic tools (for example, AFLP), especially in non-hybrid, sexually reproducing species.

Together with recent studies (for example, Matsuura et al., 2009), our study suggests that eusocial insect species displaying mixed modes of reproduction associated with different castes are likely to help us 
understand the pros and cons of sexual and asexual reproduction systems, and unravel the basis of caste determination.

\section{Conflict of interest}

The authors declare no conflict of interest.

\section{Acknowledgements}

We thank J Grangier for help in the lab; B Facon and three anonymous reviewers for useful comments on earlier versions of this paper; A Gilabert, B Gauffre and M Galan for support. The microsatellite data were partly produced through the molecular genetic analysis technical facilities of the IFR119 «Montpellier Environnement Biodiversité $\gg$. This study was financially supported by a grant from the French Ministère de l'Ecologie et du Développement Durable-appel d'offre ECOTROP to $\mathrm{AE}$ and $\mathrm{JO}$.

\section{References}

Anderson KE, Gadau J, Mott BM, Johnson RA, Altamirano A, Strehl C et al. (2006). Distribution and evolution of genetic caste determination in Pogonomyrmex seed-harvester ants. Ecology 87: 2171-2184.

Anderson KE, Linksvayer TA, Smith CR (2008a). The causes and consequences of genetic caste determination in ants (Hymenoptera: Formicidae). Myrmecol News 11: 119-132.

Anderson KE, Novak SJ, Smith JF (2008b). Populations composed entirely of hybrid colonies: bidirectional hybridization and polyandry in harvester ants. Biol J Linn Soc 95: 320-336.

Bargum K, Sundstrom L (2007). Multiple breeders, breeder shifts and inclusive fitness returns in an ant. Proc R Soc B Biol Sci 274: 1547-1551.

Baudry E, Kryger P, Allsopp M, Koeniger N, Vautrin D, Mougel $\mathrm{F}$ et al. (2004). Whole-genome scan in thelytokous-laying workers of the Cape Honeybee (Apis mellifera capensis): central fusion, reduced recombination rates and centromere mapping using half-tetrad analysis. Genetics 167: 243-252.

Bell G (1982). The Masterpiece of Nature: The Evolution and Genetics of Sexuality. University of California Press: Berkeley.

Crozier RH, Pamilo P (1996). Evolution of Social Insect Colonies: Sex Allocation and Kin Selection. Oxford University Press: Oxford.

Foucaud J, Fournier D, Orivel J, Delabie JHC, Loiseau A, Le Breton J et al. (2007). Sex and clonality in the little fire ant. Mol Biol Evol 24: 2465-2473.

Foucaud J, Jourdan H, Le Breton J, Loiseau A, Konghouleux D, Estoup A (2006). Rare sexual reproduction events in the clonal reproduction system of introduced populations of the little fire ant. Evolution 60: 1646-1657.

Fournier D, Estoup A, Orivel J, Foucaud J, Jourdan H, Le Breton $\mathrm{J}$ et al. (2005a). Clonal reproduction by males and females in the little fire ant. Nature 435: 1230-1235.

Fournier D, Foucaud J, Loiseau A, Cros-Arteil S, Jourdan H, Orivel J et al. (2005b). Characterization and PCR multiplexing of polymorphic microsatellite loci for the invasive ant Wasmannia auropunctata. Mol Ecol Notes 5: 239-242.

Fraser VS, Kaufmann B, Oldroyd BP, Crozier RH (2000). Genetic influence on caste in the ant Camponotus consobrinus. Behav Ecol Sociobiol 47: 188-194.

Goudet J (2001). FSTAT, a program to estimate and test gene diversities and fixation indices (version 2.9.3). Available from http://www.unil.ch/izea/softwares/fstat.html. Updated from Goudet (1995)
Helms Cahan S, Julian GE, Rissing SW, Schwander T, Parker JD, Keller L (2004). Loss of phenotypic plasticity generates genotype-caste association in harvester ants. Curr Biol 14: 2277-2282.

Helms Cahan S, Keller L (2003). Complex hybrid origin of genetic caste determination in harvester ants. Nature 424: 306-309.

Helms Cahan S, Vinson SB (2003). Reproductive division of labor between hybrid and nonhybrid offspring in a fire ant hybrid zone. Evolution 57: 1562-1570.

Himler AG, Caldera EJ, Baer BC, Fernández-Marín H, Mueller UG (2009). No sex in fungus-farming ants or their crops. Proc R Soc B Biol Sci 276: 2611-2616.

Hölldobler B, Wilson EO (1990). The Ants. Harvard University Press: Cambridge, MA.

Hughes WOH, Sumner S, Borm SV, Boomsma JJ (2003). Worker caste polymorphism has a genetic basis in acromyrmex leafcutting ants. Proc Natl Acad Sci USA 100: 9394-9397.

Jemielity S, Gräff J, Keller L (2006). How to fool a virgin: artificial dealation triggers oviposition in virgin Lasius niger queens. Insectes Soc 53: 323-325.

Julian GE, Fewell JH, Gadau J, Johnson RA, Larrabee D (2002). Genetic determination of the queen caste in an ant hybrid zone. Proc Natl Acad Sci USA 99: 8157-8160.

Kearney M, Shine R (2004). Developmental success, stability, and plasticity in closely related parthenogenetic and sexual lizards (Heteronotia, Gekkonidae). Evolution 58: 1560-1572.

Komaru A, Tawagashi T, Konishi K (1998). Cytological evidence of spontaneous androgenesis in the freshwtaer clam Corbicula leana Prime. Dev Genes Evol 208: 46-50.

Kummerli R, Keller L (2007). Reproductive specialization in multiple-queen colonies of the ant Formica exsecta. Behav Ecol 18: $375-383$.

Lively CM, Craddock C, Vrijenhoek RC (1990). Red queen hypothesis supported by parasitism in sexual and clonal fish. Nature 344: 864-866.

Lo N, Hayashi Y, Kitade O (2009). Should environmental caste determination be assumed for termites? Am Nat 173: 848-853.

Mantovani B, Passamonti M, Scali V (2001). The mitochondrial cytochrome oxidase II gene in Bacillus stick insects: ancestry of hybrids, androgenesis, and phylogenetic relationships. Mol Phylogenet Evol 19: 157-163.

Matsuura K, Vargo EL, Kawatsu K, Labadie PE, Nakano H, Yashiro $\mathrm{T}$ et al. (2009). Queen succession through asexual reproduction in termites. Science 323: 1687.

Maynard Smith J (1978). The Evolution of Sex. Cambridge University Press: Cambridge.

McKone MJ, Halpern SL (2003). The evolution of androgenesis. Am Nat 161: 641-656.

Normark BB (2003). The evolution of alternative genetic systems in insects. Annu Rev Entomol 48: 397-423.

Ohkawara K, Kakayama M, Satoh A, Trindl A, Heinze J (2006). Clonal reproduction and genetic caste differences in a queen-polymorphic ant, Vollenhovia emeryi. Biol Lett 2: 359-363.

Oldroyd BP, Allsopp MH, Gloag RS, Lim J, Jordan LA, Beekman $M$ (2008). Thelytokous parthenogenesis in unmated queen honeybees (Apis mellifera capensis): central fusion and high recombination rates. Genetics 180: 359-366.

Orivel J, Grangier J, Foucaud J, Le Breton J, Andres F-X, Jourdan $\mathrm{H}$ et al. (2009). Ecologically heterogeneous populations of the invasive ant Wasmannia auropunctata within its native and introduced ranges. Ecol Entomol 34: 504-512.

Pearcy M, Hardy O, Aron S (2006). Thelytokous parthenogenesis and its consequences on inbreeding in an ant. Heredity 96: 377-382.

Pichot C, El Maataoui M, Raddi S, Raddi P (2001). Surrogate mother for endangered Cupressus. Nature 412: 39-39.

Queller DC, Strassmann JE (1998). Kin selection and social insects. Bioscience 48: 165-175. 
Schilder K, Heinze J, Gross R, Holldobler B (1999). Microsatellites reveal clonal structure of populations of the thelytokous ant Platythyrea punctata (F-Smith) (Hymenoptera; Formicidae). Mol Ecol 8: 1497-1507.

Schwander T, Helms Cahan S, Keller L (2007a). Characterization and distribution of Pogonomyrmex harvester ant lineages with genetic caste determination. Mol Ecol 16: 367-387.

Schwander T, Keller L (2008). Genetic compatibility affects queen and worker caste determination. Science $\mathbf{3 2 2}$ 552-55.

Schwander T, Keller L, Helms Cahan S (2007b). Two alternate mechanisms contribute to the persistence of interdependent lineages in Pogonomyrmex harvester ants. Mol Ecol 16: 3533-3543.

Smith CR, Anderson KE, Tillberg CV, Gadau J, Suarez AV (2008). Caste determination in a polymorphic social insect: nutritional, social, and genetic factors. Am Nat 172: 497-507.

Tennant LE (1994). The ecology of Wasmannia auropunctata in primary tropical rainforest in Costa Rica, Panama. In: Williams DF (ed). Exotic Ants: Biology, Impact, and Control of Introduced Species. Westview Press: Boulder, CO, USA. pp 80-90.
Tinti F, Scali V (1996). Androgenetics and triploids from an interacting parthenogenetic hybrid and its ancestors in stick insects. Evolution 50: 1251-1258.

Ulloa-Chacon P (1990). Biologie de la reproduction chez la petite fourmi de feu Wasmannia auropunctata (R.) (Hymenoptera: Formicidae), PhD Thesis, Université de Lausanne, pp 161.

Ulloa-Chacon P, Cherix D (1988). Quelques aspecs de la biologie de Wasmannia auropunctata (Roger) (Hymenoptera, Formicidae). Actes Colloq Insectes Soc 4: 177-184.

Umphrey GJ (2006). Sperm paratism in ants: selection for interspecific mating and hybridization. Ecology 87: 2148-2159.

Volny VP, Gordon DM (2002). Genetic basis for queen-worker dimorphism in a social insect. Proc Natl Acad Sci USA 99: 6108-6111.

Vorburger C, Lancaster M, Sunnucks P (2003). Environmentally related patterns of reproductive modes in the aphid Myzus persicae and the predominance of two 'superclones' in Victoria, Australia. Mol Ecol 12: 3493-3504.

Vrijenhoek RC (1993). The origin and evolution of clones versus the maintenance of sex in Poeciliopsis. J Hered 84: 388-395.

Wetterer JK, Porter SD (2003). The little fire ant, Wasmannia auropunctata: distribution, impact, and control. Sociobiology 42: 1-41.

Supplementary Information accompanies the paper on Heredity website (http://www.nature.com/hdy) 